\title{
Research on the Characteristics of Population Agglomeration in Beijing-Tianjin-Hebei Metropolitan Area and Its Optimization Countermeasures
}

\author{
Xiaoxiao Zhang \\ School of Economics and Management, Beijing Jiaotong University, Beijing 100044, China \\ sherryzhang17@163.com
}

\begin{abstract}
Keywords: population agglomeration; evolution characteristics; policy suggestion; Beijing-Tianjin-Hebei metropolitan area
\end{abstract}

\begin{abstract}
This paper uses the population density, the disequilibrium index method and the population flow trend analysis method to analyze the population agglomeration and its evolution characteristics of Beijing-Tianjin-Hebei metropolitan area. The results show that the population of the metropolitan area continues to focus on the central cities, the core-periphery pattern is still significant. So, this paper puts forward policy recommendations in order to optimize the spatial distribution of regional population and promote the coordinated development of Beijing, Tianjin municipalities and Hebei province.
\end{abstract}

\section{Introduction}

The research on Beijing-Tianjin-Hebei metropolitan area is a hot area of the current urban and regional economics. Beijing-Tianjin-Hebei metropolitan area is one of the three major metropolitan areas, but also China's political, cultural, scientific and technological center[1]. But the development of the metropolitan area has a remarkable imbalance[2,3]. On the one hand, as the rapid development of economy and population agglomeration, the central cities, like Beijing and Tianjin, are facing with the problem of "big city diseases", such as serious traffic congestion, environment worsening, city management pressure and so on; on the other hand, the urbanization process of peripheral cities is slow and economic development in peripheral cities significantly lags behind the central cities. Therefore, this paper starts from the regional population agglomeration, analyses the characteristics of population agglomeration and evolution of Beijing-Tianjin-Hebei metropolitan area by the population density, the disequilibrium index and the population flow trend analysis methods, and puts forward some optimization suggestions, in order to promote the coordinated development of Beijing, Tianjin municipalities and Hebei Province.

\section{Research Method and Data Sources}

\subsection{Population Density and Disequilibrium Index}

Population density refers to the number of population in unit land area, which can reflect the overall distribution of population. The disequilibrium index can further reflect the differences in the spatial distribution of the population[4]. Its formula is as follows:

$$
\mathrm{V}=\sqrt{\frac{\sum_{\mathrm{i}=1}^{\mathrm{n}}\left[\frac{\sqrt{2}}{2}\left(\frac{P_{i}}{P}-\frac{s_{i}}{s}\right)\right]^{2}}{n}}
$$

Where: $\mathrm{n}$ is the number of administrative areas; $P_{i}, S_{i}$ is respectively the population and area of the i area. $\mathrm{P}, \mathrm{S}$ is respectively the sum of the population and the area of each administrative region; $\mathrm{V}$ represents the population distribution disequilibrium index, the greater the $\mathrm{V}$ value, the more concentrated population distribution, whereas, the more dispersed.

\subsection{Population Flow Trend Analysis Method}

To a certain extent, the trend of population mobility reflects the attractiveness of the population, especially the attraction degree to the foreign population. Its formula is as follows: 


$$
\mathrm{U}=\frac{p_{i}}{p_{h i}}
$$

Where: $\mathrm{U}$ is the resident population and household population ratio; $P_{h i}$ represents the total household population of $\mathrm{i}$ administrative region; $P_{i}$ represents the total resident population of $\mathrm{i}$ administrative region; The greater the $U$ value, the stronger the population inflow trend. $U$ greater than 1 , said the net inflow of population; $U$ less than 1 , the net outflow of population.

\subsection{Data Sources}

This paper selects 13 cities in Beijing-Tianjin-Hebei metropolitan area as a research sample. The data are mainly from the "China City Statistical Yearbook" (2004-2015), part of the population data obtained from the fifth census in 2000, the sixth census data in 2010 and the City Bureau of Statistics websites of each city.

\section{The Spatial Distribution and Evolution Characteristics of Metropolitan Area}

First, the total population of the metropolitan area continues to grow, and the population distribution pattern is relatively stable. According to statistical data, the total population of the metropolitan area continued to grow during the period of 2000-2014. The population grew from 90 million in 2000 to 111 million in 2014, which average annual growth rate is $1.50 \%$. Although the population of the metropolitan area has continued to increase, its population distribution pattern is relatively stable. From the metropolitan area population density distribution map in 2000 and 2014 (Figure 1), we can know that Beijing and Tianjin are always the two largest population centers in the metropolitan area. In 2014, Beijing, Tianjin's population density has more than 1200 people / sq km; while Chengde, whose population density is the lowest, is only 89.3 people / square kilometers, which is about $1 / 15$ of Beijing's population density.
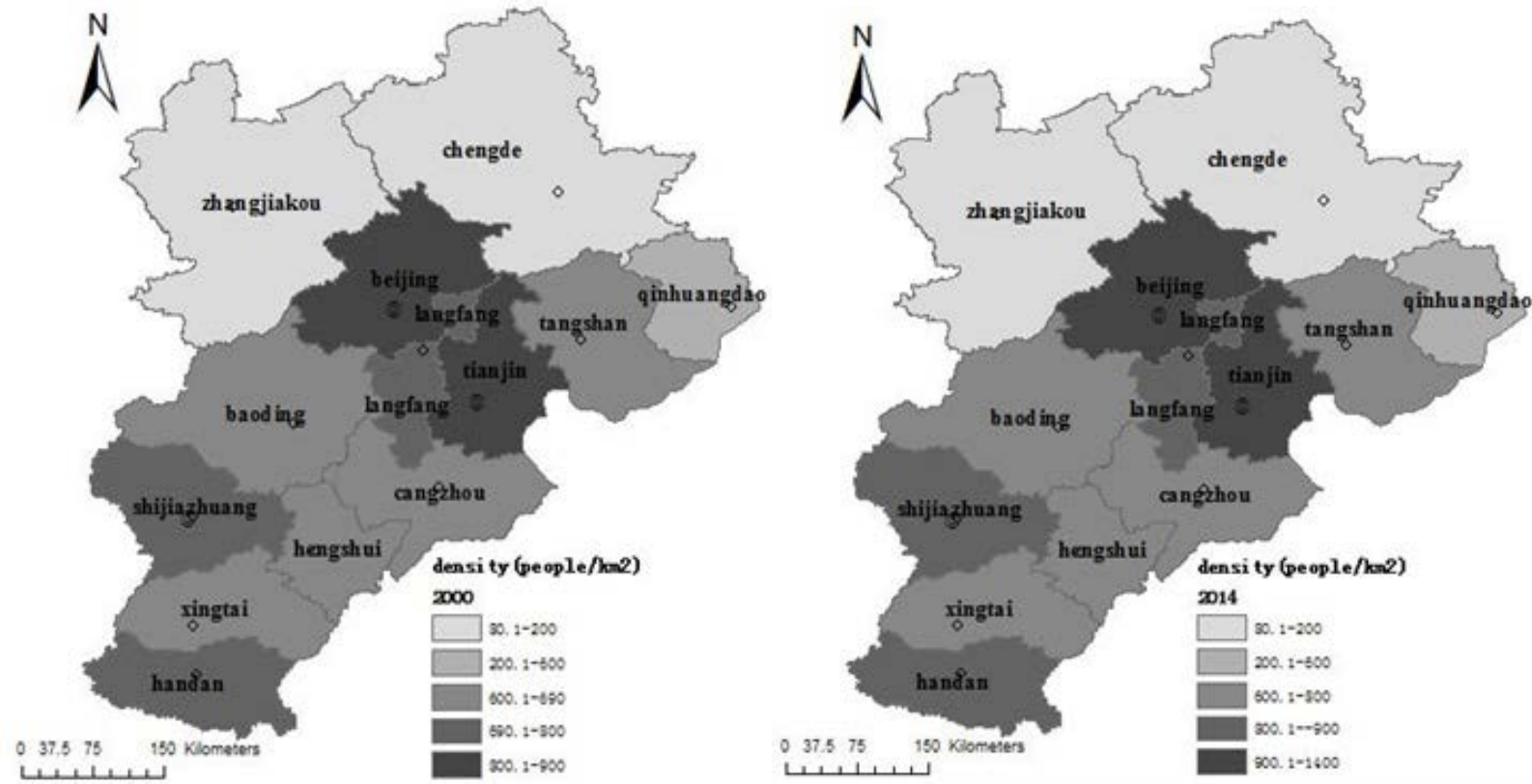

Fig. 1 Population Density Distribution of the Metropolitan Area in 2000 and 2014

Second, the trend of population mobility within the metropolitan area shows the difference of time and space. The agglomeration of urban population is mainly derived from the inflow of external population. It can be seen from Figure 2 that the trend values of population movement in Beijing and Tianjin were both greater than 1 and increased year by year, which shows that foreign population continues to flow into Beijing and Tianjin, and the growth rate of foreign population increased year by year; The U values of Tangshan, Shijiazhuang and Qinhuangdao are 1.031, 1.036 and 1.038, respectively, which means that the trend of population inflow is weak; and The U values of Baoding, Zhangjiakou, Chengde, Cangzhou, Hengshui, Xingtai are all less than 1, which means that they are all population net outflow areas. 


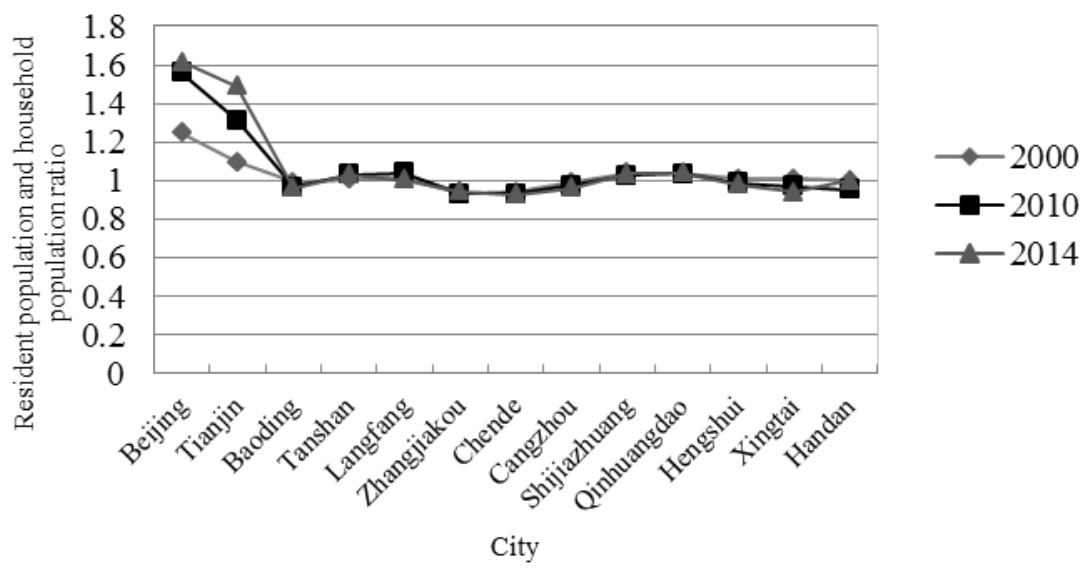

Fig. 2 the Trend of Population Flow in Metropolitan Area

Third, the disequilibrium index of the population distribution of the metropolitan area increases year by year, and the core-periphery pattern is still significant[5]. According to the disequilibrium index formula, the disequilibrium indexes of the population agglomeration of the metropolitan area during 2003-2014 were calculated. From Figure 3, we see that the population agglomeration of metropolitan area is increasing continuously, and the distribution of population still presents the obvious core-periphery pattern.

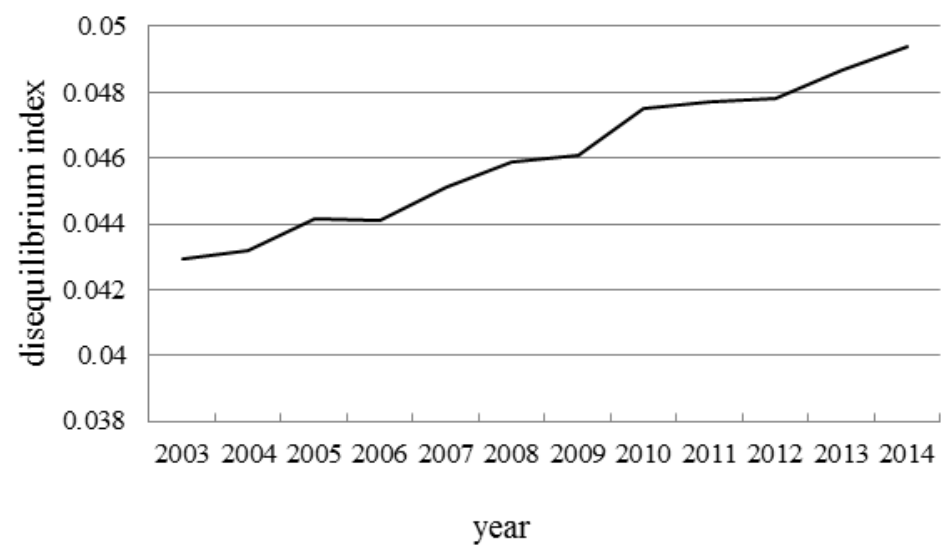

Fig. 3 the Change of population Disequilibrium Index in Metropolitan Area during 2003-2014

\section{Conclusion and Policy Suggestion}

This paper uses the population density, the disequilibrium index method and the population flow trend analysis method to analyze the population agglomeration and its evolution characteristics of Beijing-Tianjin-Hebei metropolitan area. The results show that the population of the metropolitan area continues to focus on the central cities, the core-periphery pattern is still significant. In order to optimize the spatial distribution of regional population and promote the coordinated development of Beijing, Tianjin and Hebei, this paper puts forward the following policy recommendations:

First of all, the center cities of metropolitan area should focus on the economic quality and efficiency, and optimizing the industrial development system, so as to alleviate the excessive population growth caused by the economic development. In the face of the problem of "big city diseases", the center cities of the metropolitan area can not only restrict the population agglomeration by administrative means, but also should start from the important factors of the population agglomeration, economic factors, to ease the rapid growth of the population caused by the economic development. The center cities' economic development must be compatible with the city strategic positioning. The government should make it clear what industries need to focus on development and what industries need to be resolutely eliminated, and accelerate the construction of high-end, service-oriented, agglomeration, integration, low carbon industrial development system. 
Second, the peripheral cities of metropolitan area should follow the inherent laws of the population agglomeration, and speed up the cultivation of new growth poles by the policy support, industrial development, infrastructure improvement and other aspects. Firstly, the government should clear its own position, not excessively intervene the economic development[6], but to strengthen the construction of its public service functions, such as improving the personnel training mechanism, encouraging enterprises for independent innovation, improving fiscal policies to increase the enterprise's financial discount etc., and make efforts to provide a good policy environment for the new growth pole cultivation of the metropolitan area. Next, the peripheral cities should focus on fostering emerging industries and special industries. On the premise of full consideration of regional social environment and the carrying capacity of resources, the government should carry out scientific and reasonable industrial layout, so that the industrial development can show regional characteristics, but also can gather high-quality resources in production area, and realize the development of industry to promote population agglomeration. Last, it's needed to strengthen the construction of key infrastructure. The government should actively guide the quality education and medical institutions distributed in the periphery cities, improve the public transport infrastructure and other public resources, so as to improve population agglomeration ability.

Finally, Beijing, Tianjin and Hebei should strengthen cooperation and mutual assistance in various fields. Local governments should consciously break the barriers of administrative divisions, and actively seek cooperation and mutual assistance across the region; accelerate industrial docking collaboration, form a reasonable distribution of regional industries, and avoid industrial homogeneity and vicious competition between cities; focus on building a modern transportation network system, and speed up the formation of the interconnection of integrated transport network; actively promote the integration of the three places of public services; actively promote the metropolitan area's ecological environment prevention, realizing the sustainable development of the metropolitan area.

\section{Acknowledgements}

This work was financially supported by the Beijing Municipal Social Science Fund Projects (13JDCSD002), and Major projects of the National Social Science Fund (13\&ZD026).

\section{References}

[1] Sun Tieshan, Li Guoping, and Lu Minghua, Concentration and Decentralization of Population in the Beijing-Tianjin-Hebei Metropolitan Region and Its Determinants: A Regional Density Function Approach, Acta Geographica Sinica, vol. 64 (2009) 956-966.

[2] Song Zhijie, Bo Xiaoying, and Xu Lei, Research on the Growth Pole Selection and Cultivation Problems under the Coordinated Development of the Beijing-Tianjin-Hebei Region, Journal of Hebei University of Economics and Business, vol.37 (2016) 115-123.

[3] Zhao Hong, The Strategic Reflection on Accelerating the Harmonious Development of the Capital under the New Normal, Economy and Management, vol. 30 (2016) 14-18.

[4] Duan Xuejun, Zhang Wei, and Tian Fang, A Study on the Optimization of Population Distribution of Yangtze River Delta Region on the Background of Integration in the Region, Resources and Environment in the Yangtze Basin, vol. 21 (2012) 789-796.

[5] Friedmann J, Wolff G, World City Formation: An Agenda for Research and Action, International Journal of Urban and Regional Research, vol. 3 (1982) 309-344.

[6] Zhang Yaojun, Jing Wenkai, and Li Shuo, Urbanization Trend Based on Population Spatial Distribution in China, Henan Social Sciences, vol. 24 (2016) 108-114. 